\title{
Association of Body Composition, Heart Rate and Aerobic Fitness of Mid-Age Males with Active Lifestyle
}

\author{
Prof. Sagarika Bandyopadhyay ${ }^{1}$ Mr. Sujoy Birbanshi ${ }^{2}$ Dr. Arkapal \\ Bandyopadhyay ${ }^{3}$ \\ ${ }^{1}$ Professor, Department of Physical Education, Visva-Bharati, Santiniketan, India \\ ${ }^{2}$ Research Scholar, Department of Physical Education, Visva-Bharati, Santiniketan, India \\ ${ }^{3}$ Junior Resident, Department of Pharmacology, Moti Lal Nehru Medical College, Allahabad, U.P., India
}

\begin{abstract}
:
Background: Mid-age people are very susceptible to lose baseline fitness while active life-style is a key to prevent ageing-related hypokinetic and degenerative diseases. Awareness of such scientific facts and application of these in practice are essential in the grass root level. Hardly research works in this area on apparently healthy people are conducted on mid-age people in India. Therefore it deems reasonable to investigate the status of aerobic fitness of morning walker mid-age people in relation to their body composition and resting heart rate.
\end{abstract}

Objective: The purpose of the study was to establish the relationship among body mass index, resting heart rate and aerobic fitness of mid age males.

Materials and Methods: 60 middle-aged males who undergo regular physical activities and ranging the age from 36-45 years participated as subjects of the study. Selected parameters for the study were body composition (BMI), resting heart rate (HR), aerobic fitness $(A F)$ and age of subjects. BMI was calculated by using standard method in $\mathrm{kg} / \mathrm{m}^{2}$; resting heart rate (HR) was measured by palpation at the radial artery in beats/min.; and aerobic fitness $(A F)$ was measured by '3-min step in place' test in beats/min. Pearson's Product Moment Correlation was used to find out the relationship among the variables. The level of significance was set at 0.05 .

Findings: $B M I$ and $A F^{\prime} r^{\prime}=0.266(<0.05) ; B M I$ and $H R$ ' $r$ ' $=-0.256(<0.05) ; A F$ and $H R$ ' $r$ ' $=0.035(>0.05)$.

Result \& Conclusion: In this study, statistically significant result is observed between BMI and Aerobic fitness and negative correlation is found between BMI \& HR while no significant relationship of resting Heart rate is established with Aerobic fitness of the mid-age subjects.

Key Words: Active life style, Aerobic fitness, Body Composition, Heart Rate, Mid Age Men

\section{Introduction:}

Middle aged people are a vulnerable group of population where ageing begins to show its effect. It is also the age where a large number of other diseases set to start. A healthy and physically fit middle aged man leading an active life style has a better outcome on ageing-related health problems than a person with sedentary life style, obesity and other co morbid factors. Hence physical fitness has a better effect in these individuals.

Ageing is a variable process and is characterized by decreased physical fitness which in turn leads to decreased ability to work (Shvartz and Reibold 1990). It can occur at different age in different individuals and also vary within different individuals of same age. Studies have revealed that after age of 35 yrs ageing starts deteriorating the functional capacities of the body. Shephard, Roy J. (1998) studied that yearly mortality begins to increase more noticeably from age of 40 yrs onwards due to ageing related health problems.

Aerobic fitness is considered as the most important health fitness component. It is an ability of the body to the utilization of oxygen during exercise (L. Chaddock et al., 2011) which gradually decreases with ageing. Variation in heart rate is also a predictor of mortality, independent of major cardiovascular risk factors (European Heart Journal, 1997).

In India research work in this area of concern in middle age group people are limited, therefore it was deemed reasonable to undertake this study.

\section{Objective of the study}

To establish the inter-relationship amongst body mass index, resting heart rate, aerobic fitness, age, height and weight of mid-age men. 


\section{Materials and Methods}

Subjects: The study was conducted on 60 mid age males, ranging the age between 36 and 45 years. Study area: The subjects were chosen from different districts namely, Birbhum, Bardhaman and WestMedinipur of West-Bengal, India. Criterion measures: BMI was calculated by standard formula in $\mathrm{kg} / \mathrm{m}^{2}$; Resting HR was counted by a palpation of radial artery and aerobic fitness was recorded from '3-minute Step in place test' in beats/minutes. Pearson's Product Moment Correlation was adopted to establish relationships among selected variables.

\section{Findings and Result}

The descriptive statistics of personal data and selected parameters of mid-age subjects is presented in Table I:

Table 1: Descriptive Statistics of Personal data of Subjects and Selected Parameters

\begin{tabular}{|c|c|c|}
\hline Parameters & Mean & SD \\
\hline Height (mt) & 1.60 & 0.08 \\
\hline Weight (kg) & 56.58 & 7.06 \\
\hline Age (year) & 39.61 & 3.02 \\
\hline BMI (kg.mt $\left.{ }^{-2}\right)$ & 22.22 & 3.22 \\
\hline Heart Rate (beats. $\min ^{-1}$ ) & 76.10 & 3.75 \\
\hline Aerobic Fitness (beats. $\min ^{-1}$ ) & 122.55 & 13.71 \\
\hline
\end{tabular}

Table I depicts that the mean height and weight of mid-age subjects were $1.60 \pm 0.08$ meters and $56.58 \pm 7.06$ kilograms respectively. Further, the mean and standard deviation of scores in selected parameters of chronological age, body mass index (BMI), heart rate (HR) and aerobic fitness (AF) were $39.61 \pm 3.02$, $22.22 \pm 3.22 \mathrm{~kg} . \mathrm{mt}^{-2}, 76.10 \pm 3.75$ beats $/ \mathrm{min}, 122.55 \pm 13.71$ beats $/ \mathrm{min}$ respectively.

Figure 1: Graphical representation of Selected Parameters

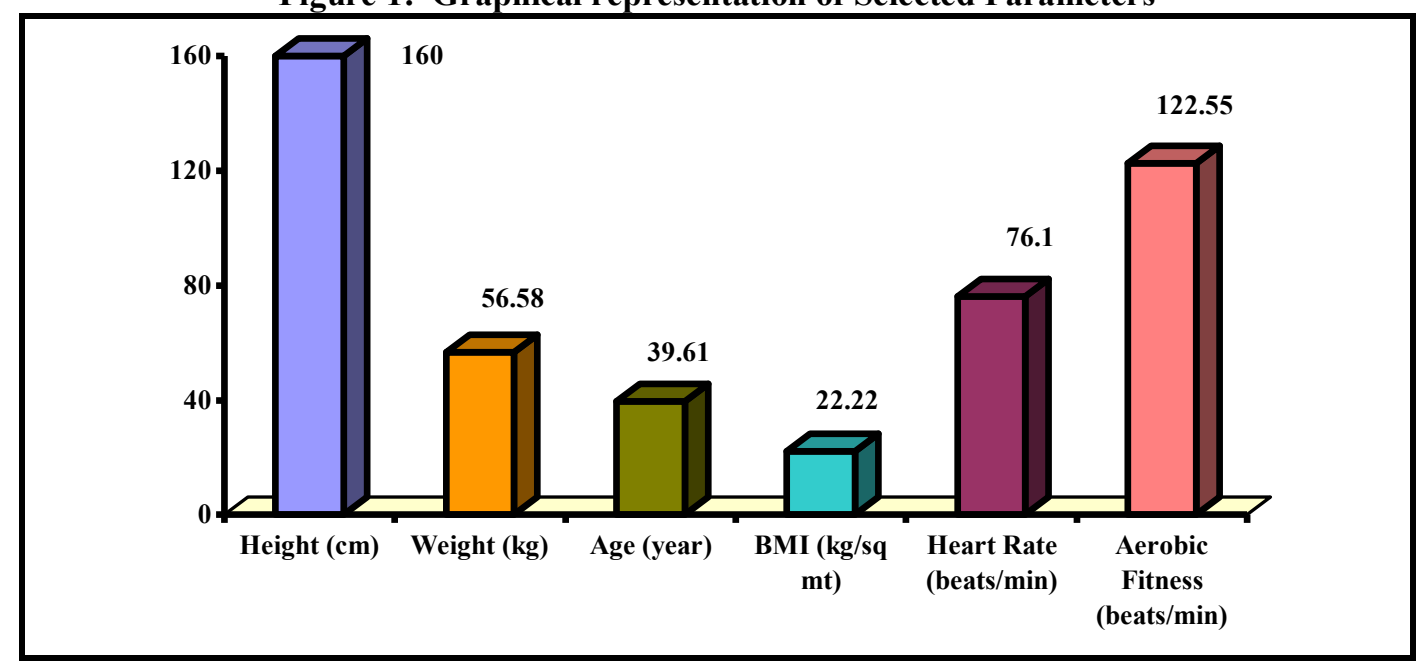

Table 2 Relationship among Selected Variables of Mid-age Men

\begin{tabular}{|l|r|r|r|r|r|r|}
\hline & \multicolumn{1}{|c|}{$\begin{array}{c}\text { Aerobic } \\
\text { Fitness }\end{array}$} & \multicolumn{1}{c|}{ Age } & \multicolumn{1}{c|}{ Height } & Weight & \multicolumn{1}{c|}{ BMI } & \multicolumn{1}{c|}{$\begin{array}{c}\text { Heart } \\
\text { Rate }\end{array}$} \\
\hline Aerobic Fitness & 1 & .237 & -.178 & .164 & $\mathbf{. 2 6 7 *}$ & .035 \\
\hline Age & .237 & 1 & $\mathbf{- . 3 0 6}$ & -.101 & .125 & .120 \\
\hline Height & -.178 & -.306 & 1 & .132 & $\mathbf{- . 5 6 5}$ & .099 \\
\hline Weight & .164 & -.101 & .132 & 1 & $\mathbf{. 7 3 9}$ & -.236 \\
\hline BMI & .267 & .125 & -.565 & .739 & 1 & -.256 \\
\hline Heart Rate & .035 & .120 & .099 & -.236 & $\mathbf{- . 2 5 6}$ & 1 \\
\hline
\end{tabular}

$*$ Significant at 0.05 level; $r(\mathrm{df}=58)=0.25$

The r-value (0.267) between aerobic fitness and BMI is found significant at 0.05 level as the tabulated value is greater than the critical value. Negative and significant relationship are observed between age $\&$ height (-.306) and height \& BMI (-.565), while correlation is positively significant between BMI and weight (.739) of the subjects. Further, the BMI is observed significantly negative with heart rate (-.256) of the mid-age men.

However, no significant relationship are established between aerobic fitness and heart rate (0.035); age and BMI (0.125), height and weight (0.132), aerobic fitness and age (0.237), height and heart rate (0.099), aerobic fitness and height (-0.178), weight and age (-0.101), aerobic fitness and weight $(0.164)$, heart rate and age $(0.120)$, heart rate and weight $(-0.236)$ of the mid-age subjects. 
Figure 2: Graphical representation of relationship amongst selected variables

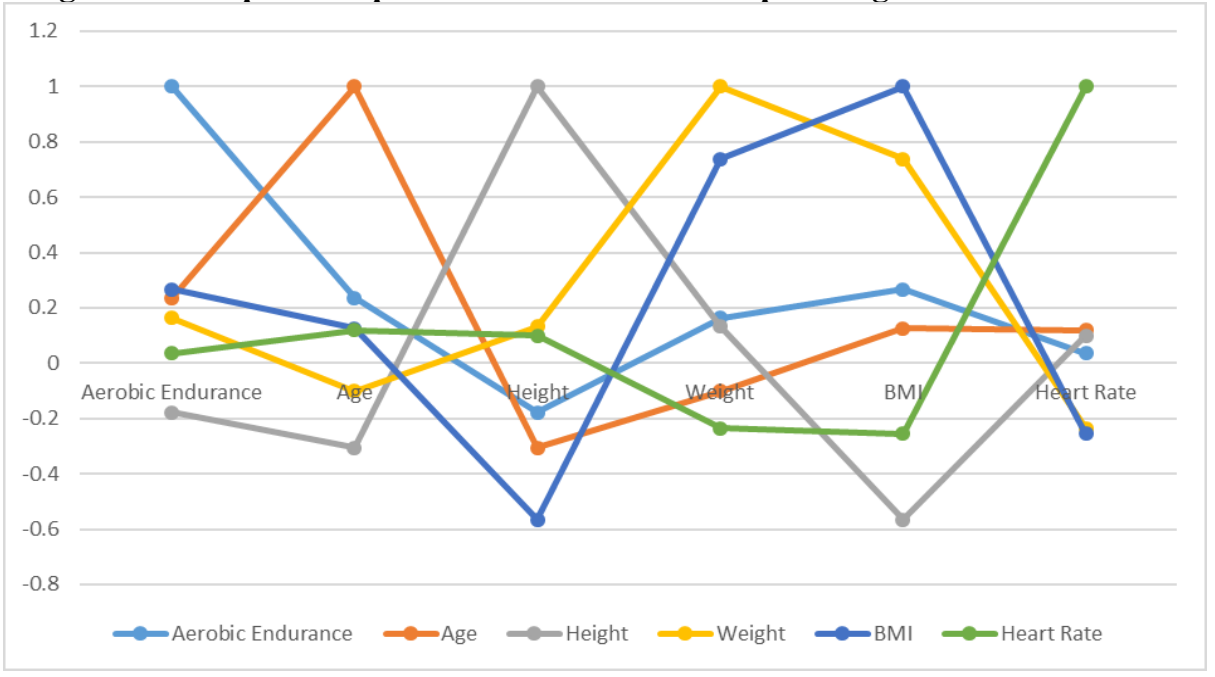

IV. Discussion:

The finding of the study indicates BMI has positive correlation with the body weight and negative relationship with the height. It means the striking effects of weight and height ratio on BMI. Further, the study shows positive relationship between BMI and aerobic fitness. This observation is in the line with the findings of Laxmi C.C. et al (2014) who found a significant positive correlation between BMI and QCT pulse rate during Queen's college step test $(r=.63 \& \mathrm{p}<0.01)$ on younger subjects. However, this study contradicts with the observation of Bandyopadhyay A. et al (2003) who worked on "Body composition, morphological characteristics and their relationship with cardio-respiratory fitness" and observed a significant negative correlation between $\mathrm{BMI}$ and $\mathrm{VO}_{2} \mathrm{max}(\mathrm{ml} / \mathrm{kg} / \mathrm{min})(\mathrm{r}=-0.48, \mathrm{p}<0.01)$.

\section{Conclusion:}

Within the limitations of the study, it may be concluded that the Body Mass Index (BMI) play a vital role in health and fitness of mid-age population which is significantly related to their aerobic fitness. However, negative correlation is observed between body mass index and heart rate of subjects in this study.

\section{Reference:}

[1]. Bandyopadhyay A, Chatterjee S. "Body composition, morphological characteristics and their relationship with cardiorespiratory fitness"; Ergonomics SA 2003; 1: 19-27

[2]. Barbosa.F.J, Benchimol-B.P.R, Cordovil I. "Autonomic modulation of the heart in systemic arterial hypertension". Arq Bras Cardiol. 2002;78(2):189-95

[3]. Blair S, Kampert J, Kohl H III, et al. "Influences of cardio-respiratory fitness and other precursors on cardiovascular disease and allcause mortality in men and women"; JAMA 1996; 276: 205-210 www.indiana.edu/blair\%20cardiovascular\%20disease\%201996.pdf

[4]. Blair et al. "Cardio-respiratory fitness is known to be as strong predictor of mortality as physical activity both in the normal population and in the population with a cardiovascular disease"; www.indiana.edu/blair\%20cardiovascular\%20disease\%201996.pdf

[5]. European Heart Journal; 18: 1997,1823-1828

[6]. Gorner K., Boraczynski T., Stihec J., "Physical activity, Body Mass Index, Body Composition and the level of aerobic capacity among young adult women and men", Sport SPA Vol.6, Issue 2: 7-14, http://en.wikipedia.org/wiki/Middle_age

[7]. Gabriela.A.T, Paulo.R. Benchimo.B., Jurandir.N. "Effects of Age and Aerobic Fitness on Heart Rate Recovery in Adult Men" www.scielo.br/pdf/abc/2012nahead/en aop06812.pdf

[8]. H. Douard, E. Parrens, M. A. Billes, L. Labbe, E. Baudet and J. P. Broustet "Predictive factors of maximal aerobic capacity after cardiac transplantation". European Heart Journal (1997) 18, 1823-1828

[9]. Hakkinen, Arja et.al. "Association of physical fitness with health-related quality of life in Finnish young men"; Health and Quality of Life Outcomes 2010, 8:15; 29 January 2010, http://www.hqlo.com/content/8/1/15

[10]. Jacobs DR, Liu K. "Cardiorespiratory fitness in young adulthood and the development of cardiovascular disease risk factors". JAMA 2003;290:3092-3100

[11]. Laura Chaddock, Matthew B. Pontifex, Charles H. Hillman, Arthur F. Kramer1. "A Review of the Relation of Aerobic Fitness and Physical Activity to Brain Structure and Function in Children"; Journal of the International Neuropsychological Society (2011), 17, $1-11$.

[12]. Laxmi CC, Udaya IB, Vinutha Shankar S "Effect of body mass index on cardio respiratory fitness in young healthy males" International Journal of Scientific and Research Publications, Volume 4, Issue 2, February 2014 ISSN 2250-3153

[13]. Myers J, Prakash M, Froelicher V, Do D, Partington S, Atwood E. "Exercise capacity and mortality among men referred for exercise testing". N Engl J Med 2002; 346: 793-801.

[14]. M. Esco, R. Herron, S. Carter and A. Flatt, "Association of Body Composition and Aerobic Fitness on Heart Rate Variability and Recovery in Young-Adult Black Men," International Journal of Clinical Medicine, Vol. 4 No. 12, 2013, pp. 532-538. doi: 10.4236/ijcm.2013.412092. 
[15]. Peter.K. and Jonathan.M "Exercise and Physical Activity: Clinical Outcomes and Applications" ISSN: 0009-7322. Online ISSN: 1524-4539 Downloaded from http://circ.ahajournals.org

[16]. Prabha S, BV Padmanabha, BR Doddamani "Correlation between obesity and cardio respiratory fitness" International Journal of Medical Science and Public Health | 2013 | Vol 2 | Issue 2. DOI: 10.5455/ijmsph.2013.2.298-302

[17]. Shekharappa Kanavi Roopa et.al. "Correlation between body mass index and cardiovascular parameters in obese and non-obese in different age groups", International Journal of Biological \& Medical Research.5.http://en.wikipedia.org/wiki/Middle_age

[18]. Shvartz E, Reibold RC. "Aerobic fitness norms for males and females aged 6 to 75 years: a review". 1990 Jan;61(1):3-

[19]. Shvartz E, Reibold RC. "Aerobic fitness norms for males and females aged 6 to 75 years: a review". Aviat Space Environ Med 1990; 61: 3-11

[20]. Shephard, Roy J. (7 March 1998). "Aging and Exercise". Encyclopedia of Sports Medicine and Science (T.D.Fahey). Retrieved 2007-06-26.

[21]. Tuomi K, Ilmarinen J, Martikainen R, Aalto L, Klockars M. “Aging, work, life-style and work ability among Finnish municipal workers in 1981-1992”. Scand J Work Environ Health 1997a; 23 (suppl 1); 58-65.

Waters Keyonia, Afram Christopher, Jenkins Sharelle "The Relationship Between Body Mass Index and Cardiovascular Responses To Racism" www.ncur20.com/presentations/9/934/paper.pdf.

[22]. www.ncbi.nlm.nih.gov/pubmed/2405832 